\title{
Optimal effect-site concentration of remifentanil when combined with dexmedetomidine in patients undergoing cystoscopy
}

\author{
Bongha Heo, Minsun Kim, Hyunjung Lee, Sanghee Park, and Seongwook Jeong \\ Department of Anesthesioloy and Pain Medicine, Chonnam National University Hospital, Gwangju, Korea
}

Background: Cystoscopic procedure is a very common practice in the field of urology due to its ability to survey the bladder for a variety of indications. However, patients who undergo cystoscopy feel intense pain and discomfort. This study investigated the half maximal effective concentration $\left(\mathrm{EC}_{50}\right)$ of remifentanil in preventing cystoscope insertion pain under sedation using dexmedetomidine.

Methods: The study was prospectively conducted on 18 male patients, aged 18 to 65 . Remifentail infusion was initiated together with dexmedetomidine, and started at a dose of $2.4 \mathrm{ng} / \mathrm{ml}$ on the first patient. The effect-site concentration $\left(\mathrm{C}_{\mathrm{e}}\right)$ of remifentanil for each subsequent patient was determined by the previous patient's response using Dixon's upand-down method with an interval of $0.3 \mathrm{ng} / \mathrm{ml}$. Patients received a loading dose of $1.0 \mu \mathrm{g} / \mathrm{kg}$ dexmedetomidine over 10 minutes, followed by a maintenance dose of $0.6 \mu \mathrm{g} / \mathrm{kg} / \mathrm{hr}$. After the patient's OAA/S score (Observer's Assessment of Alertness/Sedation scale) reached 3-4, and the $\mathrm{C}_{\mathrm{e}}$ of remifentanil reached target concentration, the urologist was allowed to insert the cystoscope and the pain responses were observed.

Results: The effect-site concentration of remifentanil required to prevent cystoscope insertion pain in 50\% of patients under sedation using dexmedetomidine was $1.30 \pm 0.12 \mathrm{ng} / \mathrm{ml}$ by Dixon's up-and-down method. The logistic regression curve of the probability of response showed that the $\mathrm{EC}_{50}$ and $\mathrm{EC}_{95}$ values ( $95 \%$ confidence limits) of remifentanil were 1.33 $\mathrm{ng} / \mathrm{ml}(1.12-1.52 \mathrm{ng} / \mathrm{ml})$ and $1.58 \mathrm{ng} / \mathrm{ml}(1.44-2.48 \mathrm{ng} / \mathrm{ml})$, respectively.

Conclusions: Cystoscopic procedure can be carried out successfully without any pain or adverse effects by optimal remifentanil effect-site concentration $\left(\mathrm{EC}_{50}, 1.33 \mathrm{ng} / \mathrm{ml} \mathrm{EC}_{95}, 1.58 \mathrm{ng} / \mathrm{ml}\right)$ combined with sedation using dexmedetomidine. (Korean J Anesthesiol 2014; 66: 39-43)

Key Words: Cystoscopy, Dexmedetomidine, Monitored anesthesia care, Remifentanil.

Received: June 25, 2013. Accepted: July 15, 2013.

Corresponding author: Seongwook Jeong, M.D., Ph.D., Department of Anesthesioloy and Pain Medicine, Chonnam National University Hospital, 8, Hak-dong, Gwangju 501-757, Korea. Tel: 82-62-220-6893, Fax: 82-62-232-6294, E-mail: anesman@gmail.com This article is Master's Thesis by Minsun Kim.

(c) This is an open-access article distributed under the terms of the Creative Commons Attribution Non-Commercial License (http:// creativecommons.org/licenses/by-nc/3.0/), which permits unrestricted non-commercial use, distribution, and reproduction in any medium, provided the original work is properly cited. 


\section{Introduction}

Cystoscopic procedure is a very common practice in the field of urology due to its ability to survey the bladder for a variety of indications. However, patients who undergo cystoscopy feel intense pain and discomfort. To diminish the degree of discomfort, surgeons instill $2 \%$ lidocaine gel into the urethra several minutes before the procedure, but this shows little significant effect [1].

Dexmedetomidine is a centrally acting a2-receptor agonist that can be titrated to the desired level of sedation without significant respiratory depression [2-4] and has a little analgesicsparing effect. It significantly reduces opioid requirements both during and after surgery [5-10]. Because of its analgesic properties, "cooperative sedation," and lack of respiratory depression, dexmedetomidine is increasingly being used as the main sedative drug in the field of monitored anesthesia care (MAC) [3].

Remifentanil is a potent ultra short-acting synthetic opioid with a blood-brain equilibrium half-life of 1-2 minutes. It is rapidly eliminated from the body by nonspecific tissue and plasma esterases, so it does not accumulate even in patients with hepatic or renal failure [11] and has a very short context-sensitive halftime of 3 minutes regardless of infusion time. Such advantages make remifentanil an appropriate pharmacologic agent for outpatient procedures [12]. Concentration-dependent respiratory depression is one of the adverse effects of remifentanil resembling those of other opioid drugs [13].

Remifentanil can be administered as part of an anesthesia technique called total intravenous anesthesia (TIVA) that uses computer-controlled infusion pumps in a process called target controlled infusion (TCI). A target effect-site concentration is entered as $\mathrm{ng} / \mathrm{ml}$ into the pump, which calculates its infusion rate according to the appropriate pharmacokinetic and pharmacodynamic model, which is derived from various patients. Induction levels of $4 \mathrm{ng} / \mathrm{ml}$ are commonly used, but the levels generally vary between $3-8 \mathrm{ng} / \mathrm{ml}$. In cases of certain surgical procedures that produce particularly strong stimuli, a level of up to $15 \mathrm{ng} / \mathrm{ml}$ might be needed.

The aim of this study was to determine the optimal $\mathrm{C}_{e}$ of remifentanil that reduces pain maximally with no adverse effects, such as respiratory depression, when combined with dexmedetomidine in patients undergoing cystoscopy.

\section{Materials and Methods}

This study was approved by the Institutional Review Board, and informed consent was obtained from all participants. The study was prospectively conducted on 18 male patients, aged 18 to 65 (Table 1), who were American Society of Anesthesiologists physical status I or II. Patients with significant renal and hepatic dysfunction were excluded. No premedication was administered prior to the procedure. For drug injection, a 20 gauge angiocatheter was inserted into the forearm or the dorsum of the hand, and was connected to a T-connector prior to arrival at the operating room. Upon entry into the operating room, all patients were monitored by electrocardiography, pulse oximetry, and automated noninvasive blood pressure monitors and oxygenated by facial mask with $\mathrm{O}_{2} 5 \mathrm{~L} / \mathrm{min}$.

Patients received a loading dose of $1.0 \mu \mathrm{g} / \mathrm{kg}$ dexmedetomidine over 10 minutes, followed by a maintenance dose of $0.6 \mu \mathrm{g} /$ $\mathrm{kg} / \mathrm{hr}$. The degree of sedation was evaluated using the OAA/S (Observer's Assessment of Alertness/Sedation scale) [14].

Remifentail infusion was started together with dexmedetomidine, based on Minto's pharmacokinetics and pharmacodynamics model, using a TCI device (Orchestra ${ }^{\circledR}$ Base Primea, Fresenius-Vial, France) [15]. The target effect-site concentration $\left(\mathrm{C}_{\mathrm{e}}\right)$ of remifentanil was initiated at $2.4 \mathrm{ng} / \mathrm{ml}$ on the first patient. After the patient's OAA/S score reached 3-4 and the $\mathrm{C}_{e}$ of remifentanil reached the target concentration, the urologist was allowed to insert the cystoscope. Pain from the entry of the cystoscope was assessed by the anesthesiologist using the fourpoint verbal categorical scoring system [16]: 0, none (negative response to questioning); 1, mild pain (pain reported only in response to questioning without any behavioral signs); 2 , moderate pain (pain reported in response to questioning and accompanied by a behavioral sign or pain reported spontaneously without questioning); 3 , severe pain (strong vocal response or response accompanied by facial grimacing, arm withdrawal, or tears). Scores of 2 or 3 were considered a "response," while scores of 0 or 1 were regarded as "no response."

The $\mathrm{C}_{\mathrm{e}}$ of remifentanil for each subsequent patient was determined by the previous patient's response using Dixon's up-anddown method $[17,18]$. If a patient scored "response," the $C_{e}$ of remifentanil for the subsequent patient was increased by $0.3 \mathrm{ng} /$ $\mathrm{ml}$. If a patient scored "no response," the $\mathrm{C}_{\mathrm{e}}$ of remifentanil for the subsequent patient was decreased by $0.3 \mathrm{ng} / \mathrm{ml}$.

Each patient's heart rate ( $\mathrm{HR}$, beats/min) and the mean arterial pressure (MAP, $\mathrm{mmHg}$ ) were recorded before the dexmedetomidine and remifentanil infusion (baseline, T0), $10 \mathrm{~min}$ after the dexmedetomidine and remifentanil infusion (T1), and immediately after the cystoscope insertion (T2). We assessed

Table 1. Demographic Data

\begin{tabular}{lc}
\hline Characteristics & Data \\
\hline Gender $(\mathrm{M} / \mathrm{F})$ & $18 / 0$ \\
Age $(\mathrm{yr})$ & $48.11 \pm 13.96$ \\
Height $(\mathrm{cm})$ & $168.70 \pm 5.96$ \\
Weight $(\mathrm{kg})$ & $70.67 \pm 11.68$ \\
ASA class (I/II) & $10 / 8$ \\
\hline
\end{tabular}

Values are mean \pm SD or number of patients. ASA: American Society of Anesthesiologists. 
the complications related to dexmedetomidine and remifentanil, such as hypotension (decrease in MAP to $<55 \mathrm{mmHg}$ ), bradycardia (HR slower than 40 beats/min), chest wall rigidity, oxygen desaturation $\left(\mathrm{SpO}_{2}\right.$ below $\left.90 \%\right)$, and dizziness. In case of hypotension, ephedrine $0.25 \mathrm{mg} / \mathrm{kg}$ was prepared to be administered, and atropine $0.5 \mathrm{mg}$ was prepared for bradycardia. For possible chest wall rigidity and oxygen desaturation, mask ventilating devices were prepared.

Patient data are presented as median and range or mean \pm $\mathrm{SD}$. The $\mathrm{EC}_{50}$ of remifentanil was determined by using Dixon's up-and-down method, which calculates the mean of the midpoint dose of all independent pairs of patients who manifested a crossover from "response" to "no response" after six crossover points. Probit analysis enabled us to derive a dose-response curve and confidence intervals, and estimated $\mathrm{EC}_{50}$ and $\mathrm{EC}_{95}$ were calculated.

SPSS (Windows ver. 18.0, SPSS Inc., Chicago, IL, USA) was used for statistical analysis. Probit regression model and Sigma Plot 10.0 were used for calculating the confidence intervals and plotting the dose-response curve. All measured values were denoted as the mean $\pm \mathrm{SD}$, number of patients and mean $(95 \%$ confidence intervals, CI). Serial changes of mean arterial pressure and heart rate were analyzed by repeated measures ANOVA. Statistical significance was defined as $\mathrm{P}<0.05$.

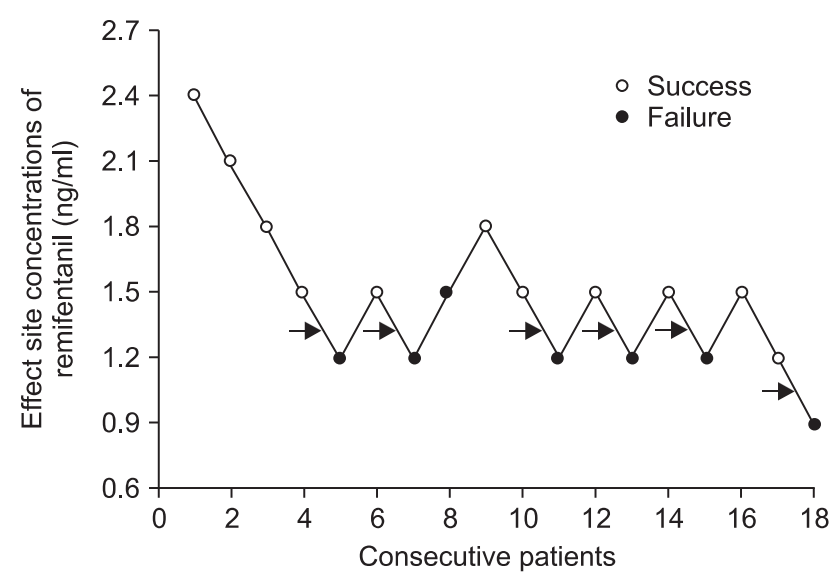

Fig. 1. Responses of 18 consecutive patients in whom cystoscopy was performed and the effect-site concentrations of remifentanil. An arrow represents the mean remifentanil concentration when crossing from a success (white circle) to a failure (black circle) for preventing cystoscope insertion pain. The average of these concentrations $\left(\mathrm{EC}_{50}\right)$ was $1.30 \pm 0.12 \mathrm{ng} / \mathrm{ml}$.

Table 2. Effect-site Concentrations of Remifentanil

\begin{tabular}{lc}
\hline & Patients $(\mathrm{n}=18)$ \\
\hline $\mathrm{EC}_{50}$ by Dixon's up-and-down method $(\mathrm{ng} / \mathrm{ml})$ & $1.30 \pm 0.12$ \\
$\mathrm{EC}_{50}$ by probit regression $(\mathrm{ng} / \mathrm{ml})$ & $1.33(1.12-1.52)$ \\
$\mathrm{EC}_{95}$ by probit regression $(\mathrm{ng} / \mathrm{ml})$ & $1.58(1.44-2.48)$ \\
\hline
\end{tabular}

Values are mean \pm SD and mean (95\% confidence interval).

\section{Results}

The sequences of consecutive response and nonresponse are shown in Fig. 1.

The $\mathrm{C}_{\mathrm{e}}$ of remifentanil required to prevent cystoscope insertion pain in $50 \%$ of patients under sedation using dexmedetomidine was $1.30 \pm 0.12 \mathrm{ng} / \mathrm{ml}$ using Dixon's up-and-down method.

A logistic regression curve of the probability of response showed that the $\mathrm{EC}_{50}$ and $\mathrm{EC}_{95}$ values (95\% confidence limits) of remifentanil were $1.33 \mathrm{ng} / \mathrm{ml}(1.12-1.52 \mathrm{ng} / \mathrm{ml})$ and $1.58 \mathrm{ng} /$ $\mathrm{ml}$ (1.44-2.48 ng/ml), respectively (Table 2, Fig. 2).

Table 3 lists hemodynamic data from patients during drug infusion. No patient experienced clinically significant hemodynamic changes during the study. Even though HR and MAP showed statistically significant decreases, those were not clinical decreases. We did not need to rescue the patients from hypotension or bradycardia with ephedrine or atropine.

After the infusion of a loading dose of dexmedetomidine for $10 \mathrm{~min}$, all patients' OAA/S scores reached 4 . Significant oxygen desaturation was not observed in any patient.

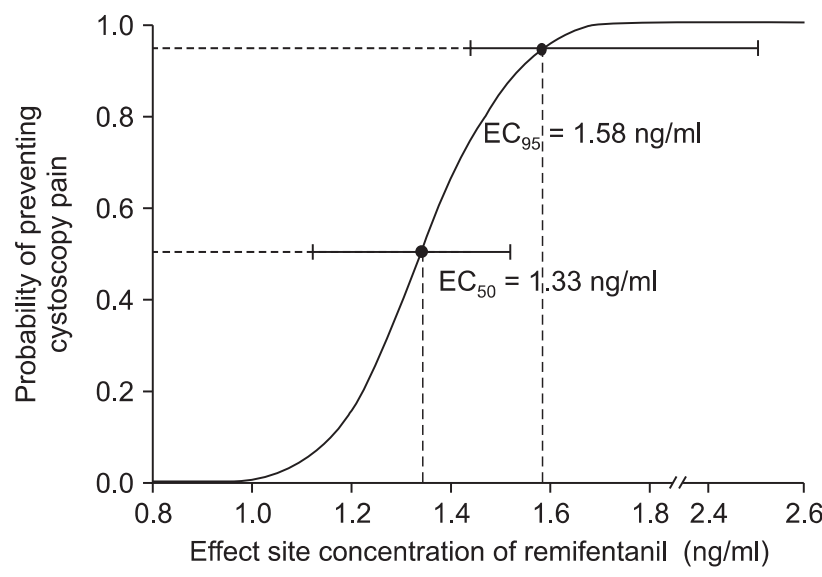

Fig. 2. Dose-response curve from the probit analysis of individual effectsite concentration of remifentanil and the reaction to cystoscopy in the patients. Horizontal bars denote $95 \%$ confidence interval for efficient effect-site concentration of remifentanil in $50 \%$ and $95 \%$ of probabilities $\left(\mathrm{EC}_{50}\right.$ and $\left.\mathrm{EC}_{95}\right)$, respectively. The upper $95 \%$ confidence limit of $\mathrm{EC}_{95}$ ranges out of the graph plane.

Table 3. Changes in Mean Arterial Pressure and Heart Rate

\begin{tabular}{cccc}
\hline Time & T0 & T1 & T2 \\
\hline MAP (mmHg) & $99.6 \pm 10.4$ & $94.7 \pm 10.9$ & $92.4 \pm 13.3^{*}$ \\
HR (beats/min) & $67.5 \pm 11.9$ & $59.2 \pm 9.2^{*}$ & $62.5 \pm 16.6$ \\
\hline
\end{tabular}

Values are represented means \pm SD. MAP: mean arterial pressure, HR: heart rate, T0: Baseline, T1: 10 min after dexmedetomidine and remifentanil infusion, T2: after insertion of cystoscope. ${ }^{*} \mathrm{P}<0.05$ compared with baseline value. 


\section{Discussion}

In this study we used dexmedetomidine and remifentanil for the cystoscopic procedure with the goal of finding the $\mathrm{C}_{\mathrm{e}}$ of remifentanil for minimizing pain during the procedure. Our results show that the $\mathrm{EC}_{50}$ of remifentanil that nearly abolishes pain during cystoscopy is $1.33 \mathrm{ng} / \mathrm{ml}$.

Cystoscopy is one of the most common procedures in urological practice. Before the mid-1990s, the rigid cystoscope was the only option for cystoscopy. A flexible cystoscope is now available for outpatient procedures, but rigid cystoscopies remain more common in Korea due to their lower expenses, more facile handling, and improved visual field. Consequently, there is a need for methods to reduce pain, fear, and anxiety in patients who undergo rigid cystoscopy.

A meta-analysis of 9 studies that included a total of 417 patients treated with intraurethral $2 \%$ lidocaine gel and 400 patients treated with intraurethral plain gel identified no statistically significant treatment effect [1].

MAC may be useful in various clinical fields such as gastrointestinal endoscopy, radiologic intervention, or minimally invasive surgical procedures. It provides suitable intraoperative conditions as well as comfort and analgesia for patients. The frequently used drugs are propofol, midazolam, or etomidate as sedatives and fentanyl, alfentanil, or remifentanil as analgesics. Infrequently, the administration of sedatives in combination with analgesics can cause significant respiratory depression.

Dexmedetomidine is a highly selective a2-adrenoceptor agonist with a specificity for the receptor that is eight times higher than that of clonidine [19]. It provides excellent sedation and analgesia with minimal respiratory depression $[2,3,5]$. A recent multicenter trial indicated that dexmedetomidine was an effective baseline sedative for patients undergoing a broad range of surgical procedures under MAC, resulting in greater patient satisfaction, lower opioid requirements, and less respiratory depression compared with placebo [20]. In patients undergoing diagnostic transesophageal echocardiography, the sedative effect of dexmedetomidine proved to be equivalent to that of the standard therapy using midazolam and fentanyl without increasing the incidence of respiratory depression or oxygen desaturation. It also seemed to be better in terms of hemodynamic results [21].

However, Muller et al. [22] have shown that dexmedetomidine alone was not as effective as propofol with fentanyl for providing conscious sedation during ERCP, and it was associated with significant hemodynamic instability and longer recovery time. In addition, Tosun et al. [23] showed that pediatric patients undergoing cardiac catheterization with dexmedetomidine and ketamine complained of insufficient sedation and analgesia and experienced prolonged recovery time compared to patients who received propofol and ketamine.
Dexmedetomidine leads to dose-dependent decreases in blood pressure, heart rate, and plasma catecholamine concentrations $[24,25]$. Higher concentrations of this drug can also result in systemic and pulmonary hypertension [3]. These adverse effects on the cardiovascular system might limit the use of high concentrations of dexmedetomidine, especially in patients with significant cardiac disease. Therefore there was a need for clinicians to find appropriate additional analgesics for effective conscious sedation or monitored anesthesia care with low concentrations of dexmedetomidine.

Kaygusuz et al. [26] have used dexmedetomidine with fentanyl safely and effectively during extracorporeal shockwave lithotripsy. De La Mora-González et al. [27] reported that the dexmedetomidine-fentanyl group did not show hemodynamic instability compared with the nalbuphine-propofol group in patients undergoing plastic surgery.

Remifentanil, a potent ultra short-acting synthetic opioid, is very popular among anesthesiologists. It can be an appropriate pharmacologic agent in combination with dexmedetomidine for outpatient procedures. Similarly to other opioids, however, remifentanil may also cause hypotension, bradycardia, chest tightening, and hypoxemia. Although very few anesthesiologists want to use dexmedetomidine with remifentanil, many studies that examined a remifentanil $\mathrm{EC}_{50}$ that could prevent hemodynamic changes, caused by endotracheal intubation or injection pain, have reported that $2.0-5.0 \mathrm{ng} / \mathrm{ml}$ of remifentanil did not induce significant hypotension, bradycardia, chest tightening, or hypoxemia [28-30].

In our study, after the administration of remifentanil and dexmedetomidine, statistically significant reductions of the mean arterial pressure and heart rate were observed. Nonetheless, hypotension and bradycardia that required treatment did not develop.

These findings should be considered within the context of the study's limitations. First, no female patients were included in this study. Female patients' pain during cystoscopy would be less than that of male patients because of their comparatively short urethra. In addition, dexmedetomidine and remifentanil will demonstrate pharmacokinetic and pharmacodynamic differences between males and females. Second, we did not compare other regimens, such as propofol-remifentanil or midazolam-remifentanil, for example. These will be of clinical benefit if they are not associated with an increase in the incidence of complications.

In conclusion, our report shows that the $\mathrm{EC}_{50}$ and $\mathrm{EC}_{95}$ of remifentanil that nearly abolish pain during cystoscopy when using dexmedetomidine at a clinical dose are $1.33 \mathrm{ng} / \mathrm{ml}$ and 1.58 $\mathrm{ng} / \mathrm{ml}$, respectively. Cystoscopic procedures can be carried out successfully without any pain or adverse effects by an optimal $\mathrm{C}_{\mathrm{e}}$ of remifentanil combined with sedation using dexmedetomidine. 


\section{References}

1. Patel AR, Jones JS, Babineau D. Lidocaine 2\% gel versus plain lubricating gel for pain reduction during flexible cystoscopy: a meta-analysis of prospective, randomized, controlled trials. J Urol 2008; 179: 986-90.

2. Hall JE, Uhrich TD, Barney JA, Arain SR, Ebert TJ. Sedative, amnestic, and analgesic properties of small-dose dexmedetomidine infusions. Anesth Analg 2000; 90: 699-705.

3. Ebert TJ, Hall JE, Barney JA, Uhrich TD, Colinco MD. The effects of increasing plasma concentrations of dexmedetomidine in humans. Anesthesiology 2000; 93: 382-94.

4. Venn RM, Hell J, Grounds RM. Respiratory effects of dexmedetomidine in the surgical patient requiring intensive care. Crit Care 2000; 4: 302-8.

5. Herr DL, Sum-Ping ST, England M. ICU sedation after coronary artery bypass graft surgery: dexmedetomidine-based versus propofolbased sedation regimens. J Cardiothorac Vasc Anesth 2003; 17: 576-84.

6. Arain SR, Ebert TJ. The efficacy, side effects, and recovery characteristics of dexmedetomidine versus propofol when used for intraoperative sedation. Anesth Analg 2002; 95: 461-6.

7. Venn RM, Grounds RM. Comparison between dexmedetomidine and propofol for sedation in the intensive care unit: patient and clinician perceptions. Br J Anaesth 2001; 87: 684-90.

8. Elbaradie S, El Mahalawy FH, Solyman AH. Dexmedetomidine vs. propofol for short-term sedation of postoperative mechanically ventilated patients. J Egypt Natl Canc Inst 2004; 16: 153-8.

9. Abdalla MI, Al Mansouri F, Bener A. Dexmedetomidine during local anesthesia. J Anesth 2006; 20: 54-6.

10. Taghinia AH, Shapiro FE, Slavin SA. Dexmedetomidine in aesthetic facial surgery: improving anesthetic safety and efficacy. Plast Reconstr Surg 2008; 121: 269-76.

11. Glass PS, Hardman D, Kamiyama Y, Quill TJ, Marton G, Donn KH, et al. Preliminary pharmacokinetics and pharmacodynamics of an ultra-short-acting opioid: remifentanil (GI87084B). Anesth Analg 1993; 77: 1031-40.

12. Song D, White PF. Remifentanil as an adjuvant during desflurane anesthesia facilitates early recovery after ambulatory surgery. J Clin Anesth 1999; 11:364-7.

13. Pattinson KT. Opioids and the control of respiration. Br J Anaesth 2008; 100: 747-58.

14. Chernik DA, Gillings D, Laine H, Hendler J, Silver JM, Davidson AB, et al. Validity and reliability of the Observer's Assessment of Alertness/ Sedation Scale: study with intravenous midazolam. J Clin Psychopharmacol 1990; 10: 244-51.

15. Minto CF, Schnider TW, Egan TD, Youngs E, Lemmens HJ, Gambus PL, et al. Influence of age and gender on the pharmacokinetics and pharmacodynamics of remifentanil. I. Model development. Anesthesiology 1997; 86: 10-23.

16. King SY, Davis FM, Wells JE, Murchison DJ, Pryor PJ. Lidocaine for the prevention of pain due to injection of propofol. Anesth Analg 1992; 74: 246-9.

17. Dixon WJ. Efficient analysis of experimental observations. Annu Rev Pharmacol Toxicol 1980; 20: 441-62.

18. Dixon WJ. Staircase bioassay: the up-and-down method. Neurosci Biobehav Rev 1991; 15: 47-50.

19. Bhana N, Goa KL, McClellan KJ. Dexmedetomidine. Drugs 2000; 59: 263-8.

20. Candiotti KA, Bergese SD, Bokesch PM, Feldman MA, Wisemandle W, Bekker AY. Monitored anesthesia care with dexmedetomidine: a prospective, randomized, double-blind, multicenter trial. Anesth Analg 2010; 110: 47-56.

21. Cooper L, Candiotti K, Gallagher C, Grenier E, Arheart KL, Barron ME. A randomized, controlled trial on dexmedetomidine for providing adequate sedation and hemodynamic control for awake, diagnostic transesophageal echocardiography. J Cardiothorac Vasc Anesth 2011; 25: 233-7.

22. Muller S, Borowics SM, Fortis EA, Stefani LC, Soares G, Maguilnik I, et al. Clinical efficacy of dexmedetomidine alone is less than propofol for conscious sedation during ERCP. Gastrointest Endosc 2008; 67: 651-9.

23. Tosun Z, Akin A, Guler G, Esmaoglu A, Boyaci A. Dexmedetomidine-ketamine and propofol-ketamine combinations for anesthesia in spontaneously breathing pediatric patients undergoing cardiac catheterization. J Cardiothorac Vasc Anesth 2006; 20: 515-9.

24. Kallio A, Scheinin M, Koulu M, Ponkilainen R, Ruskoaho H, Viinamäki O, et al. Effects of dexmedetomidine, a selective alpha 2-adrenoceptor agonist, on hemodynamic control mechanisms. Clin Pharmacol Ther 1989; 46: 33-42.

25. Bloor BC, Ward DS, Belleville JP, Maze M. Effects of intravenous dexmedetomidine in humans. II. Hemodynamic changes. Anesthesiology 1992; 77: 1134-42.

26. Kaygusuz K, Gokce G, Gursoy S, Ayan S, Mimaroglu C, Gultekin Y. A comparison of sedation with dexmedetomidine or propofol during shockwave lithotripsy: a randomized controlled trial. Anesth Analg 2008; 106: 114-9.

27. De La Mora-González JF, Robles-Cervantes JA, Mora-Martinez JM, Barba-Alvarez F, Llontop-Pisfil Ede L, Gonzalez-Ortiz M, et al. Hemodynamic effects of dexmedetomidine--fentanyl vs. nalbuphine--propofol in plastic surgery. Middle East J Anesthesiol 2012; 21 : 553-7.

28. Lee B, Lee JR, Na S. Targeting smooth emergence: the effect site concentration of remifentanil for preventing cough during emergence during propofol-remifentanil anaesthesia for thyroid surgery. Br J Anaesth 2009; 102: 775-8.

29. Kim JS, Kim DH, Min SK, Kim KM, Kim JY. Comparison of effect-site concentration of remifentanil for tracheal intubation with the lightwand and laryngoscopy during propofol target-controlled infusion. Korean J Anesthesiol 2011; 60: 393-7.

30. Lee BW, Kim SH, So KY. The effect of gender on EC(50) of remifentanil to prevent pain during injection of microemulsion propofol. Korean J Anesthesiol 2012; 63: 504-9. 